\title{
A equidade da formação docente na modalidade a distância
}

\author{
The equity of teacher training in distance education
}

\author{
La equidad de la formación docente na modalidade a distancia
}

\author{
LUCILA MARIA COSTI SANTAROSA* \\ DEBORA CONFORTO**
}

\begin{abstract}
RESUMO
Este artigo problematiza os desafios enfrentados por pessoas com deficiência em contextos de formação a distância, com o objetivo de sintonizar essa modalidade de ensino às contemporâneas configurações da escola tecnológica e inclusiva. O Curso de Formação de Professores em Tecnologias Digitais Acessíveis operou como corpus de análise para que o campo de conhecimento da acessibilidade e da usabilidade fosse discutido e explicitado na organização curricular e gerencial desse espaço de formação. Ao aproximar o discurso e a prática da inclusão em processos educacionais para sistemas Web, as estratégias de reconhecimento das especificidades humanas implementadas conduziram ao desenvolvimento de uma plataforma digital acessível. Esse processo e a customização de materiais didáticos e de flexibilização curricular ilustram os resultados que consolidam ações de inclusão essenciais e eletivas no âmbito da educação a distância.
\end{abstract}

Palavras-chave: Formação docente. Educação a distância. Pessoas com deficiência. Acessibilidade à Web.

\begin{abstract}
This article discusses the challenges which people with diverse needs face in the contexts of distance education in order to adjust this method to the contemporary settings of the inclusive technological school. The Teacher Continuing Education Course in Accessible Communication and Information Technology is the corpus of the analysis of this article to debate and explain accessibility and usability in the course program organization and management. By putting theory and practice of inclusion together in the educational processes for Web systems, the strategies for acknowledgment of the human specificities allowed the development of an accessible digital platform. This platform increased the autonomous access and use of the services and resources available for the teachers with diverse needs. The development of an accessible digital platform, customization of teaching materials and curriculum flexibility show the results that consolidation of the essential and electives inclusive actions in the distance education context. Keywords: Teacher training. Distance education. People with disabilities. Web accessibility.
\end{abstract}

\begin{abstract}
RESUMEN
Este artículo aborda los desafíos que enfrentan las personas con discapacidad en la formación a distancia, con el fin de ajustar este tipo de educación a los valores contemporáneos de la escuela tecnológica e incluyente. El Curso de Formación del Profesorado de Tecnología Accesible digitales sirvió como elemento de análisis para el campo del conocimiento, acceso y uso, fue discutido y explicado en el plan de estudios y la organización de gestión de esta área de formación. Al acercarse el discurso y la práctica de la inclusión en los procesos educativos para los sistemas Web, estrategias de reconocimiento de las especificidades humanos implementadas, llevó al desarrollo de una plataforma digital accesible. El desarrollo de una plataforma digital accesible, la personalización de los materiales de enseñanza y la flexibilidad curricular ilustran los resultados que consolidan las acciones de inclusión esenciales y optativas en el contexto de la educación a distancia.
\end{abstract}

Palabras clave: Formación docente. Educación a distancia. Personas con discapacidad. Accesibilidad Web.

\footnotetext{
*Bolsa-Produtividade em Pesquisa CNPq. Doutora em Educação pela Universidade Federal do Rio Grande do Sul. Professora, orientadora, pesquisadora da UFRGS, nos cursos de Pós-Graduação em Educação e no Pós-Graduação em Informática na Educação. Coordenadora do Núcleo de Pesquisa em Informática na Educação Especial - NIEE/UFRGS. Vice-presidente da Redespecial Internacional. Presidente de Honra e Fundadora da ONG Redespecial Brasil. Representante do Brasil na Red Iberoamericana de Infomártica Educativa. E-mail: <lucila.santarosa@ufrgs.br>. <http://www.niee.ufrgs.br>.

**Doutora em Educação. Especialista em Informática na Educação e em Modelagem de Software Educacional. Graduada em Ciências Biológicas. Atua como pesquisadora da RedEspecial Brasil e do NIIE/UFRGS.E-mail: < deboraconforto@gmail.com>.
} 


\section{INTRODUÇÃO}

As repercussões socioculturais provocadas por ações pedagógicas devem ser analisadas, entre tantos outros aspectos, pela capacidade de formar profissionais para o sistema educacional brasileiro com condições de construir respostas às demandas que emergem em um mundo cada vez mais globalizado e tecnológico. O Curso de Formação de Professores em Tecnologias Digitais Acessíveis surgiu como um dos possíveis movimentos sintonizados com o desafio de instrumentalizar educadores para a apropriação técnica e metodológica de recursos digitais presentes na escola, uma das ações de qualificação docente patrocinadas pelo Fundo Nacional de Desenvolvimento da Educação (FNDE).

Um curso de formação docente deve ser projetado no sentido de promover processos de encontros entre profissionais, provocar mudanças em práticas pedagógicas cristalizadas, fomentar acontecimentos que aproximem educadores de estratégias inovadoras para o cenário educacional brasileiro. Entre tantas confluências traçadas no decorrer de quase 15 anos de capacitação, na modalidade a distância $(\mathrm{EaD})$, promovida pelo Núcleo de Informática na Educação Especial (NIEE), da Universidade Federal do Rio Grande do Sul (UFRGS), não se poderia deixar de destacar as provocadas pela presença de professores com deficiência nesse contexto de formação docente. Por meio das especificidades desses profissionais, um campo de conhecimento manifestado na estrutura curricular do curso conquistou um sentido ainda maior, a Acessibilidade à Web. A relação entre a teoria e a prática foi explicitada nas dificuldades relacionadas ao acesso e à interação com as ferramentas disponibilizadas pelas tradicionais plataformas para a educação a distância (EaD). O que evidenciou a quase impossibilidade de formar, no âmbito das tecnologias digitais, professores com deficiência para atuar nas Salas de Recursos, com o Atendimento Educacional Especializado (AEE).

$O$ frágil sentido de pertencimento vivenciado por esses docentes que se afastavam dos padrões de normalidade, historicamente impostos pela sociedade, revelou a necessidade de aprofundar as discussões sobre os modelos e interfaces eleitos para mediar processos de capacitação em EaD. Este artigo, ao problematizar muitos dos desafios sob os quais são submetidos professores com limitações físicas e sensórias em cursos de formação na modalidade EaD, apresenta os procedimentos adotados para otimizar e potencializar a capacitação/interação de educadores com e sem deficiência. Uma operação que culminou na modelagem e implementação de uma plataforma acessível - Place - desenvolvida em sintonia com as recomendações de acessibilidade propostas pelo Consórcio World Wide Web (W3C, 2009).
Para a equipe de programadores do NIEE/UFRGS, o diferencial dessa discussão revela-se ao detalhar as ações de acessibilidade, termo que desponta no contexto da citricultura, e mesmo não estando registrado nos dicionários da língua portuguesa, vem sendo utilizado no âmbito discursivo da tecnologia: acessibilizar, verbo constituído com base no adjetivo latino accessibilis; acessibilização, substantivo que indica ato e efeito de permitir o acesso.

As estratégias de acessibilização de um sistema Web indicadas no decorrer deste artigo foram analisadas e validadas em um Curso de Formação de Professores em Tecnologias Digitais Acessíveis, no qual educadores brasileiros iniciam o processo de conquista da fluidez digital para mediar processos de inclusão escolar e social de alunos com deficiências, matriculados nas redes públicas de ensino no Brasil.

\section{ACESSIBILIDADE NA FORMAÇÃO A DISTÂNCIA: SABERES E PRÁTICAS}

Essa nova realidade impressa pelo desenho da instituição escolar inclusiva e tecnológica conduziu educadores a interagirem com estudantes com deficiência, sem que ao menos detivessem conhecimentos sobre a temática da inclusão ou apresentassem a almejada fluência digital para a utilização dos recursos de alta e baixa tecnologia disponíveis na escola. Dessa forma, muitos professores passaram a atuar sob a perspectiva da educação inclusiva, desconhecendo o campo de pesquisa da educação especial e os diversos instrumentos tecnológicos que podem contribuir para conduzir com maior possibilidade de sucesso o processo de inclusão escolar e sociodigital.

A mutabilidade da tecnologia e a diversidade das especificidades humanas têm exigido de todo educador a construção da postura de permanente aprendiz de novos saberes, entre eles, da realidade, das demandas provocadas pela presença tecnológica e pela inclusão do públicoalvo da educação especial no sistema regular de ensino. Essas novas facetas que passam a compor o perfil dos profissionais da Educação colocam-se como necessárias para responder a um conjunto de rotinas muito diferentes das que até então vigoraram nas comunidades escolares brasileiras.

Programas de formação, na modalidade a distância, vêm sendo oferecidos para capacitar docentes na perspectiva da educação inclusiva. Mas como enfrentar os problemas naturalmente associados aos desafios colocados pela nova configuração da escola inclusiva e tecnológica, sem garantir a esses educadores, com e sem deficiência, a conquista do poder da escuta e da palavra? 
A equipe de coordenação do Curso de Formação de Professores em Tecnologia da Informação e Comunicação Acessíveis afirma sua convicção de que, somente por meio do escutar e do dialogar (FREIRE, 1996) com professores, as estratégias de capacitação poderão culminar em práticas pedagógicas alicerçadas no princípio da equidade escolar, social e cultural. Por isso, a operacionalização de cada edição do curso de formação conduzido pela equipe do NIEE/UFRGS representa o resultado do processo/produto desses movimentos de interlocução entre seus atores professores cursistas, formadores e tutores.

Como consequência dessa produção dialogada, um projeto pedagógico atento às mudanças tecnológicas e aos movimentos de inserção escolar e sociodigital foi estruturado em sintonia com os princípios da educação inclusiva (BRASIL, 2007). Permitindo, assim, acompanhar o desenvolvimento das estratégias inclusivas de educadores em formação, como também provocar a atualização e qualificação tecnológica e pedagógica do currículo do curso de formação. Aproximar professores e tecnologias acessíveis tem sido um compromisso assumido de forma permanente pela equipe do NIEE/ UFRGS, responsável pela coordenação pedagógica do curso. Aplicativos para dispositivos móveis, contemporâneos sistemas de informação e comunicação na Web, especialmente os que operam sob a lógica da computação nas nuvens, são alguns dos muitos campos de conhecimento trazidos para o curso, antecipando muitas vezes a chegada dessas configurações tecnológicas para o contexto das redes públicas de ensino.

Para o Curso de Formação de Professores em Tecnologia da Informação e Comunicação Acessíveis, a estruturação curricular (Figura 1) foi projetada em blocos temáticos, colocando em destaque um aspecto central em processos de capacitação docente, o de dar ao profissional o poder de escolha, para que ele possa desenhar seu programa de aprendizagem. Construindo, assim, a capacidade de perceber e apropriar-se dos saberes proporcionados pelo processo de formação para aproximá-los das estratégias políticas e pedagógicas da instituição educativa participante. Além de, por meio desse empoderamento docente, ampliar as possibilidades de enfrentar os desafios colocados pela presença do aluno com deficiência na sala de aula do ensino regular.

A flexibilização curricular, em especial no que tange à formação docente, tem nas palavras de Valente e de Almeida (1997, p. 19) um dos elementos impulsionadores: "Os assuntos desenvolvidos durante um curso devem ser escolhidos pelos professores, de acordo com o currículo e a abordagem pedagógica adotada pela escola".

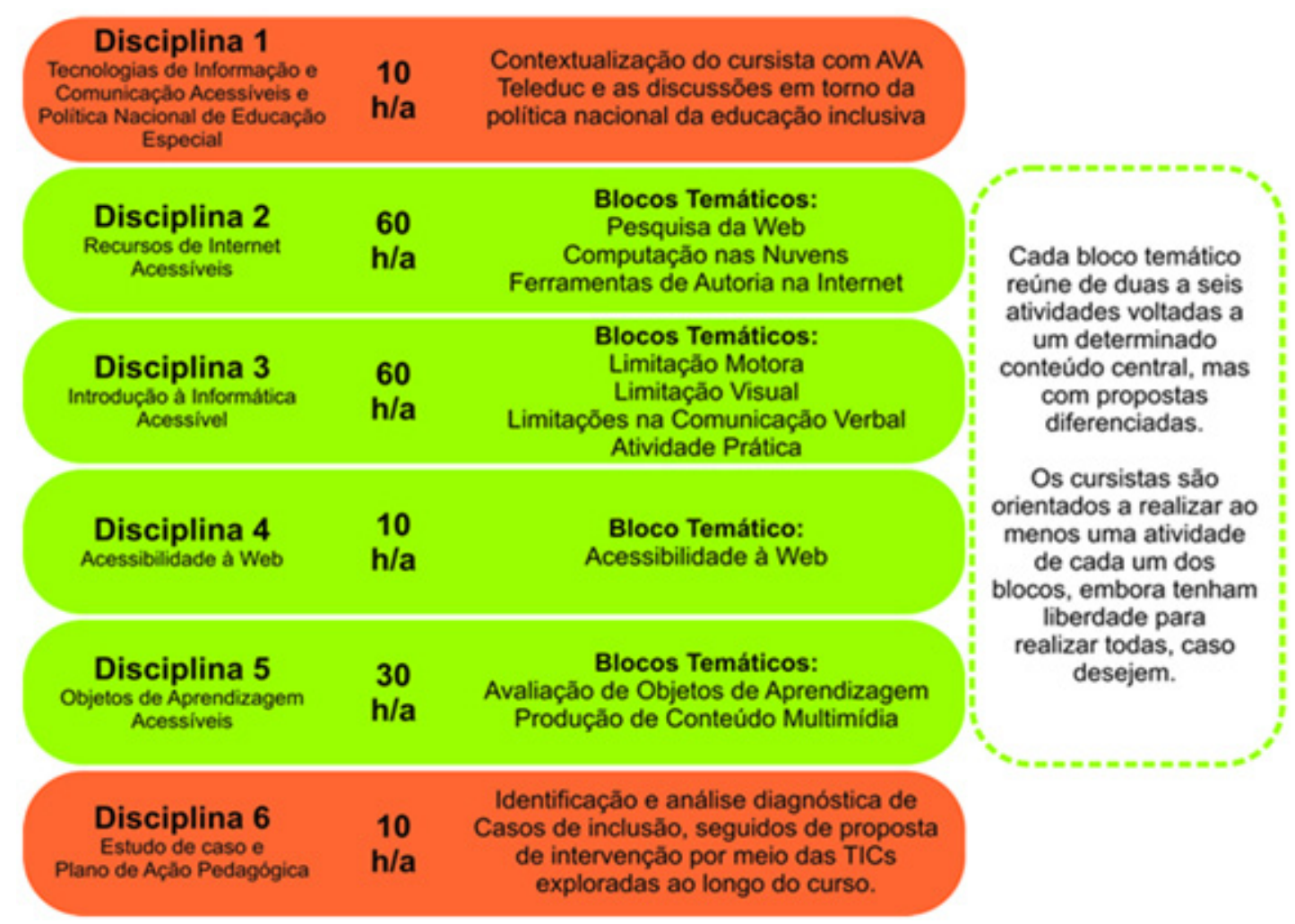

Figura 1. Estrutura curricular do Curso de Formação em Tecnologias da Informação e Comunicação Acessíveis (Fonte: NIEE/UFRGS) 
O desenho curricular estabelecido pelo curso permitiu projetar uma linha formativa sem engessar as possibilidades de aprendizagem do professor. Esse poder de escolha acerca do currículo forja uma trajetória personalizada de aprendizagem além de, também, condicionar a corresponsabilidade individual e coletiva dos participantes na construção de saberes no âmbito das tecnologias acessíveis.

A importância dada ao campo de conhecimento da Acessibilidade à Web fez com que essa temática fosse contemplada em um dos módulos do curso. Tal ação revelou-se inovadora, considerando que esse conjunto de saberes não encontra representatividade na grade curricular de muitas instituições de ensino superior.

$\mathrm{O}$ módulo de Acessibilidade à Web, pela novidade da temática e pela construção cuidadosa e dialogada do referencial teórico, desacomoda o professor em formação, fazendo-o problematizar o próprio "Universo da Internet" a partir de um novo filtro: a possibilidade de interação da pessoa com deficiência. As palavras da educadora que participou do processo de formação ratificam a relevância do foco de discussão proposto pelo curso:

“[...] Esse módulo foi muito importante, até pelo fato de ainda não termos a mínima noção do quanto é difícil para aqueles que possuem alguma limitação acessarem a Web. A realização dessas atividades nos conscientiza de que não é tão simples assim... Não é somente o Windows possuir aquelas ferramentas no painel de controle 'Acessibilidade' que estará tudo resolvido. Tem-se muito mais, e muito mais pode ser feito e garantido para diminuir as práticas de exclusão." [Professora cursista A - Edição 2013/2]

O módulo de Acessibilidade à Web impulsionou a concretização de dois importantes movimentos construídos pelos professores, ações que foram caracterizadas pelo protagonismo e pela possibilidade de ultrapassar os limites de tempo e de espaço que naturalmente demarcam um processo de formação. E o primeiro movimento foi realizado por uma docente cega ao realizar a atividade de avaliação da acessibilidade em sites. A conquista da fluência digital por parte dessa educadora autorizou-a a participar de uma conceituada lista de discussão sobre a acessibilidade promovida pela equipe Acesso Digital:

\footnotetext{
“[...] Estou fazendo um curso de tecnologias acessíveis. Nesse módulo, temos de avaliar um site a partir de uma ficha disponibilizada pelo curso. Alguém poderia me ajudar a entender os critérios dessa ficha? Escolhi analisar um site de notícias que acesso diariamente e encontro problemas: www.vnews.com.br A ficha segue em anexo, quem puder me ajudar... Existem critérios visuais que não consigo identificar. Abraços e aguardo a ajuda de vocês." [Formadora M. Edição 2013/2]
}

A busca pelo apoio de sujeitos mais experientes na temática da acessibilidade digital não deve ser entendida como um delegar de tarefa. Para um avaliador com limitação visual, verificar aspectos relacionados às recomendações de acessibilidade, principalmente quando os aspectos analisados estão associados à qualidade da cor e ao contraste do conteúdo digital, constitui-se em uma tarefa difícil, ou melhor, quase impossível. A atitude mais natural seria a professora cega encaminhar uma mensagem para a equipe de formadores, apontando para a impossibilidade de realização do item na Ficha de Avaliação de Acessibilidade e solicitando a verificação: "A combinação de cores entre o fundo e o texto das páginas era suficientemente contrastante para permitir que a informação fosse visualizada por sujeitos com limitação visual ou por usuários que possuem monitores monocromáticos".

Essa educadora buscou na lista de discussão a rede de apoio para construir a solução para o desafio de avaliar a acessibilidade digital, mas também socializou suas descobertas com os demais colegas de curso, explicitando um exemplo real de êxito do processo de inclusão. A mensagem enviada na plataforma virtual do curso revelou a ação da docente com deficiência visual na partilha do saber para qualificar o processo de análise da acessibilidade digital para os demais professores:

Amigos (as), Formadora M. e Tutora M.,

Gostei muito do conteúdo apresentado pela ficha de avaliação manual de acessibilidade em sites. Não conhecia tal referencial e será muito útil daqui pra frente. Tive dúvidas sobre a existência de mecanismos para avaliar a aparência das cores e contrastes nos sites e se haveria a possibilidade de uma análise, mesmo sendo eu deficiente visual. Então, como participo de um grupo de discussão sobre o assunto "Acessibilidade à Web", resolvi compartilhar as dúvidas com os amigos de lá, tendo em vista que alguns membros também possuem deficiência visual. Consegui uma informação bastante rica. É um avaliador que faz a análise apenas de cores e contraste, podendo ser acessado pelo link fornecido por um dos amigos de grupo: http://www.checkmycolours. $\mathrm{com} /$. Adorei e, apesar do resultado ser em inglês, podemos compreender com total facilidade. Encontrei por lá também M., formadora do curso. Que mundo pequeno e maravilhoso este! O que conseguir por lá irei compartilhando aqui. [Professora cursista B - Edição 2013/2]

O impacto social da inserção da temática de Acessibilidade à Web em programas de capacitação docente também necessita ser analisado ao operar com uma interface de atuação mais efetiva na conquista da equidade também fora da instituição escolar. A mensagem postada no fórum de discussão ilustra este segundo movimento explicitado pelos professores: o de conhecer para o de agir: 


\begin{abstract}
“[...] Acabo de assistir ao vídeo 'Acessibilidade à Web: custo ou benefício?' e, neste momento, os frutos do curso passam a transpor os muros da minha comunidade escolar. Muitas falas me chamaram a atenção, como as que cito agora: '[...] a audição não é sintética como a visão' (Leda); '[...] fazer páginas acessíveis para todas as pessoas' (Marco). Neste momento, parei para refletir sobre o site oficial da prefeitura da minha cidade e, com certeza, tentarei contribuir para torná-lo acessível [...]." [Professora cursista C - Edição 2013/2]
\end{abstract}

Educadores são atores sociais que de forma mais direta e efetiva impulsionam mudanças na sociedade. Ao mediar processos de desenvolvimento humano, alteram as relações econômicas e culturais. A mensagem encaminhada ao secretário de Comunicação de um município brasileiro pela educadora participante do curso revela que o exercício da cidadania concretiza-se quando o conhecimento conquista o poder de intervir no campo social. Ao fazer o conhecimento apreendido transpor os limites do curso e da escola, os professores exercem sua cidadania, interferindo na organização das ações de governo de cidades brasileiras:

Senhor secretário F. A.:

Sou professora municipal, atuando em Sala de Recursos Multifuncionais e oferecendo aos alunos com deficiência da rede o Atendimento Educacional Especializado (AEE). Como todo professor, estou em constante formação. Tendo a oportunidade de participar de uma capacitação, via Internet, pela UFRGS, e oferecida pelo MEC, na qual estamos discutindo e aprendendo sobre tecnologia acessível, sinto-me na obrigação, não apenas como servidora municipal, mas como cidadã que contribui com a construção de uma sociedade inclusiva, de partilhar com essa Secretaria, que mantém nossa sociedade informada sobre os acontecimentos da cidade proporcionados pela gestão municipal, que existem diretrizes internacionais para formatação de sites acessíveis. Na certeza de que esse é o objetivo do nosso secretário, tornar as informações contidas no site da prefeitura acessível a todos, coloco-me à disposição para qualquer esclarecimento e contribuição para tornar mais justo o processo de comunicação do governo municipal. [Professora cursista C - Edição 2013/2]

Esses dois movimentos, impulsionados pela dinâmica proposta pelo Curso de Formação de Professores em Tecnologia da Informação e Comunicação Acessíveis, respondem ao contemporâneo paradigma que afirma que a modelagem de sistemas para a Web - mais do que aperfeiçoar a usabilidade de suas interfaces - deve assumir como objetivo, conforme analisa O'Reilly (2005), o desenvolvimento de uma Arquitetura de Participação. Isto é, quando sistemas computacionais passam a incorporar recursos de interconexão e de compartilhamento de tecnologias, mas, especialmente, de saberes.
O processo/produto do curso de formação buscou qualificar o desenvolvimento de pessoas com deficiência, reafirmando a ideia de Santarosa e Conforto (2012) de que a tecnologia é sempre provisória, uma vez que todo recurso educacional digital invariavelmente se cristaliza e representa um estágio de desenvolvimento sociocultural da humanidade. Por meio dessa premissa, destaca-se a supremacia do homem sobre a tecnologia, posto que as escolhas tecnológicas e metodológicas assumidas pela equipe de proposição e de gerenciamento do curso foram feitas com a certeza de que: (1) a mutabilidade da tecnologia não pode ser desconsiderada, pois a acelerada atualização tecnológica faz com que, rapidamente, os recursos se tornem obsoletos; (2) os avanços sociocognitivos possibilitados pelo desenvolvimento humano projetam também um incremento no conjunto de novas habilidades e competências, que nem sempre podem ser exploradas e valorizadas por meio de recursos educacionais tradicionalmente utilizados; (3) o devir produzido na interação entre professores e tecnologias digitais institui processos de subjetivação impulsionados pela imbricada relação homem-tecnologia; (4) as permanentes reconfigurações dos tempos e dos espaços socioculturais, das sociedades primitivas, passando pela sociedade industrial e, contemporaneamente, pela informacional, são produtos e processos de tecnologias que cunharam subjetividades individuais e coletivas.

\section{INCLUSÃO ESSENCIAL E ELETIVA: A BUSCA DA EQUIDADE NA MODALIDADE EAD}

Plasticidade e dinamicidade, tão presentes no acelerado e mutável mundo tecnológico, impõem a atualização dos instrumentos de comunicação e de mediação socioculturais, em especial os relacionados com os importantes contextos de formação do homem moderno. Como a tecnologia é sempre provisória, a plataforma digital, cenário no qual são tecidos fecundos tempos e espaços de interação, de comunicação e de aprendizado, vem sendo igualmente redesenhada pela equipe de coordenação do Curso de Formação de Professores em Tecnologia da Informação e Comunicação Acessíveis. O objetivo é torná-la uma interface que explicite, como nomeados por Rodrigues (2009), os processos de inclusão essencial e eletiva.

A inclusão essencial afirma-se como a dimensão que assegura a todos os cidadãos o acesso e a participação, sem discriminação, em todos os seus níveis e serviços sociais. Pressupõe que ninguém pode ser discriminado por causa de uma condição pessoal no acesso à educação, saúde, emprego, lazer, cultura, entre outros. Essa dimensão relaciona-se diretamente com os direitos humanos e com uma acepção básica de justiça social. Por 
outro lado, a dimensão eletiva da inclusão assegura que, independentemente de qualquer condição, a pessoa tem o direito de relacionar-se e interagir com os grupos sociais em função dos seus interesses.

Ao afirmar o direito de acesso de todos os professores aos diferentes níveis e serviços sociais, a política brasileira de educação inclusiva vem demarcando a dimensão da inclusão essencial. Entretanto, o exercício da docência e a participação em processos de formação continuada para professores, com e sem deficiência, não podem ser reduzidos à mera garantia de acesso, pois é preciso que sejam dadas efetivas condições de pertencimento, inclusive na modalidade EaD. Estabelecida tal prerrogativa, faz sentido diferenciar as expressões igualdade e equidade.

Igualdade, representada pelo sinal aritmético de igual, remete à promoção de situações idênticas, uniformes e equivalentes para todas as pessoas. A palavra equidade faz referência à capacidade de apreciar e julgar com retidão, imparcialidade, justiça e igualdade diferentes ações e contextos sociais, produtos e processo de ações humanas, analisando imparcialmente cada caso para que não haja desigualdades e injustiças. Formações na modalidade $\mathrm{EaD}$ que não afirmem o conceito de equidade produzirão um processo pedagógico impassível às diferenças, tratando igualmente os desiguais.

Ao desconsiderarem esse aporte conceitual, as interfaces dos cursos na modalidade a distância podem estar projetando "guetos", na medida em que produzem a atribuição de posições e a restrição das condições de possibilidade para que cada participante trace seu percurso de aprendizagem. Assim, inevitavelmente, coloca-se a diversidade humana sob o risco da exclusão, pois, como alertam as palavras de Bourdieu (1999, p. 53), "a igualdade formal que pauta a prática pedagógica serve como máscara e justificativa para a indiferença no que diz respeito às desigualdades reais [...]".

Os movimentos de inclusão sociocultural não podem demarcar posições ou determinar os tempos e os espaços para a interação de professores com limitações quando em práticas de formação na modalidade a distância. Essa tênue linha divisória que separa a inclusão/exclusão deve ser cuidadosamente observada na construção dos programas de capacitação docente pela interface das plataformas digitais. A possibilidade de interlocução entre todos os atores, formadores, tutores e professores, com e sem deficiência, somente será colocada como uma garantia quando as plataformas digitais impulsionarem ações de mediação tecnológica e metodológica edificadas sob a conquista do sentido de pertencimento.

A configuração tecnológica das tradicionais plataformas EaD exemplifica a fragilidade da dimensão da inclusão essencial discutida por Rodrigues (2009). O direito de matrícula foi dado a todos os professores, com e sem deficiência, em cursos de formação docente na modalidade a distância e pela interface das plataformas digitais. Mas as pesquisas sobre a acessibilidade à Web têm revelado que os recursos de informação e de comunicação ofertados para a modalidade $\mathrm{EaD}$ não possibilitam a todos os seus participantes o importante exercício do sentido de pertencimento (SONZA, 2007). A homogeneidade tecnológica que caracteriza os cursos na modalidade $\mathrm{EaD}$ tem colocado professores com deficiência fora das possibilidades de aprendizagem e de desenvolvimento, fazendo com que muitos deles vivenciem processos explícitos de exclusão.

As diferentes edições do Curso de Formação de Professores em Tecnologia da Informação e Comunicação Acessíveis, ao valorizar e desejar a presença de professores com deficiência, foram, paulatinamente, de acordo com as possibilidades ofertadas pelo desenvolvimento tecnológico, construindo estratégias de adaptação dos recursos digitais e da metodologia para que a inclusão essencial provocasse também uma inclusão eletiva. $\mathrm{O}$ conceito da diferença foi considerado na construção das estratégias organizacionais e gerenciais pela equipe de coordenação. Nada mais coerente para um curso que toma para si a meta de preparar docentes na perspectiva da educação inclusiva assumida na organização curricular, na seleção do material didático e no processo de avaliação.

A presença de professores cursistas surdos, cegos, com baixa visão e com limitações físicas fez com que a equipe de coordenação do curso promovesse ações de inclusão eletiva: (1) composição de um sistema de tutoria, no qual formadores e tutores dominam a Língua Brasileira de Sinais (Libras), possibilitando uma mediação mais pontual para educadores com limitação auditiva; (2) utilização de tecnologias específicas para resolver problemas de acessibilidade particulares a cada deficiência, como, por exemplo, vídeo aulas em Libras, com o detalhamento das orientações de cada atividade proposta para professores com restrições auditivas e descrição em áudio para os participantes com limitações visuais; (3) organização do material disponibilizado na plataforma do curso, respeitando as recomendações do design universal, com a construção de textos com vocabulário simples e frases curtas, uso de marcadores, descrição de imagens, utilização de glossários e estímulo ao uso de dicionários virtuais em Libras; (4) tutoriais em diferentes formatos - texto, áudio, vídeo, dinâmicos - para facilitar a apropriação técnico-metodológica de professores em formação com deficiências físicas e sensoriais; (5) emprego de linguagem simples, apresentando de forma clara e objetiva a informação de que o docente necessita; (6) uso da "língua" do 
professor cursista, traduzindo os saberes da informática para campo de comunicação do professor da educação básica, a fim de possibilitar sua apropriação conceitual; (7) minimização da sobrecarga cognitiva, por meio de uma forte ambientação à plataforma virtual do curso, familiarizando cada cursista com as funcionalidades dos recursos digitais no processo de aprendizagem; (8) estabelecimento de uma rede de apoio para utilização de diferentes recursos de comunicação, com o objetivo de solucionar dúvidas quanto à instalação e à utilização da tecnologia acessível.

Para educadores cegos ou com baixa visão foram colocadas em prática estratégias de adequação dos recursos ofertados pelo curso, principalmente em relação à descrição de imagem e/ou vídeo. Todo o material didático disponibilizado pela equipe pedagógica do curso foi organizado em páginas HTML, observando as normativas de acessibilidade estabelecidas pela equipe de pesquisadores nacionais e internacionais, registradas nas diretrizes W3C (2009): (1) etiquetagem e descrição das imagens, validação do conteúdo por leitores de tela; (2) uso de recursos alternativos para ferramentas de comunicação síncrona, como o chat acessível da Rede Saci e os recursos de comunicação instantânea Google Talk, Hangout e Skype; (3) leituras disponibilizadas no formato HTML ou TXT, permitindo o acesso às informações pelo leitor de tela; (4) reorganização ou proposição de atividades quando a tecnologia em foco de discussão se revelava inacessível ao educador cego.

Entretanto, todas as estratégias implementadas para a adequação do material didático do curso organizadas com o objetivo de garantir e qualificar a presença do professor com deficiência foram fragilizadas pela não acessibilidade da plataforma digital na qual o processo de capacitação era mediado. Para que o paradigma da Cultura da Participação pudesse operar em todo o seu potencial, também em processos de formação na modalidade a distância, como adverte O'Reilly (2005), seria preciso garantir que o número de pessoas beneficiadas por seus recursos fosse efetivamente ampliado.

A matriz conceitual que estrutura o curso - o respeito e a valorização da diversidade humana - não poderia mais aceitar a exclusão prévia de qualquer grupo social e a restrição de qualquer direito referente à pessoa com deficiência. Para que essas parcelas da humanidade, até recentemente invisíveis, pudessem conquistar espaços de sociabilidade, de formação e de trabalho, a equipe de desenvolvedores e de programadores do NIEE/UFRGS comprometeu-se com o desafio de desenvolver a Plataforma EaD Acessível - Place -, uma interface ajustada às especificidades de professores com deficiência.

\section{Place: A CONQUista da EQUidAde NA PLATAFORMA EAD}

Na edição de 2014 do Curso de Formação de Professores em Tecnologia da Informação e Comunicação Acessíveis, os primeiros passos foram dados para que o sentido de pertencimento se configurasse como uma garantia para os professores com deficiência. Esse desafio foi alcançado ao proporcionar um contexto de formação que minimizasse as barreiras de acesso e de interação impostos pelos recursos tradicionalmente disponibilizados nas plataformas utilizadas em cursos na modalidade EaD. As possibilidades de mediação pedagógica e de comunicação com autonomia foram garantidas também para os educadores com limitações visuais, auditivas e físicas pela acessibilidade da plataforma Place.

Essa interface foi implementada com o objetivo básico de disponibilizar um espaço virtual de inclusão digital para que todos os usuários pudessem exercer sua cidadania em termos de convivência e de desenvolvimento de projetos colaborativos em áreas de interesse comum. Seu diferencial em relação às demais plataformas está em ter sido projetada seguindo rigorosamente as recomendações de usabilidade e acessibilidade da W3C.

Os princípios de acessibilidade e de usabilidade orientaram a modelagem da Plataforma Place para tornar acessível a interface e a funcionalidade de seus recursos por meio de: (1) redimensionamento do texto, que passa a ser apresentado utilizando-se de recursos de ampliação e redução de fontes, independentemente do uso de uma tecnologia assistiva; (2) etiquetagem com alternativa textual para conteúdo não textual; (3) garantia de acesso por diferentes dispositivos de entrada: teclados, simuladores, acionadores, ponteiras de boca e de cabeça; (4) descrição de teclas de atalho e orientações para a sua utilização em diferentes versões de navegadores na Web; (5) proposição de mecanismos de navegação consistentes, de fácil identificação, operando de forma previsível; (6) possibilidade de acesso às funcionalidades, mantendo a mesma localização e ordem para ajudar na orientação do usuário; (7) ajuda sensível ao contexto, fornecendo informações relacionadas ao recurso em execução; (8) orientação quanto às funcionalidades da Plataforma Place, apresentadas no formato de vídeo, em Linguagem Brasileira de Sinais (Libras) e em áudio, para facilitar o acesso aos usuários cegos ou com baixa visão; (8) possibilidade de maximizar a compatibilidade com agentes de usuário através da validação da interface com leitores de tela e usuários reais com limitação visual e auditiva; (9) realização de avaliações automáticas por intermédio dos robôs de avaliação de acessibilidade - validador W3C (https://validator-suite.w3.org/) e Access 
Monitor (http://www.acessibilidade.gov.pt/accessmonitor/) - e manual, seguido da validação de usuários com diferentes deficiências, sendo este um dos mais importantes preceitos de avaliação de acessibilidade.
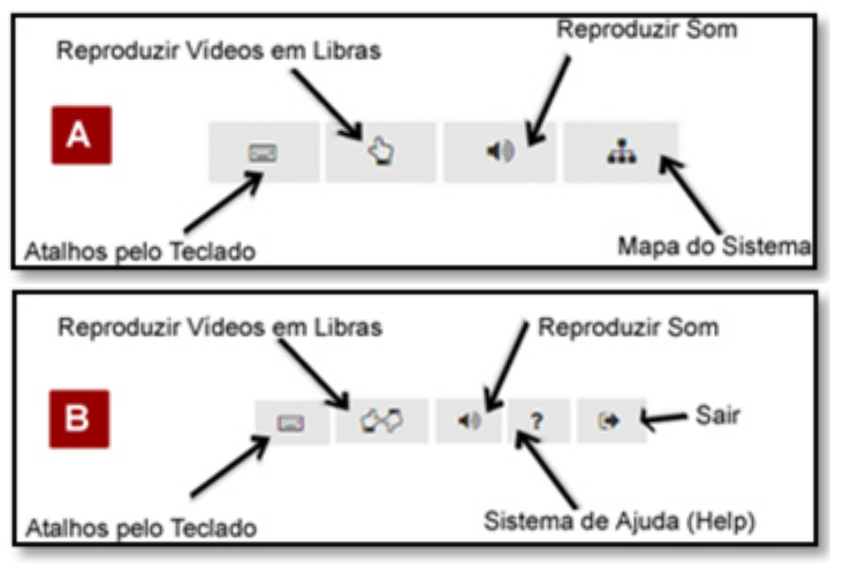

Figura 2. Barra de Acessibilidade para as páginas não logadas (A) e logadas (B)

Todas essas estratégias de acessibilidade culminaram em um projeto gráfico com design minimalista de interação amigável e intuitiva, proporcionando um melhor gerenciamento da carga cognitiva por parte do usuário. A Barra de Acessibilidade da Plataforma Place (Figura 2) representa uma aplicação do conceito de ergonomia cognitiva, ao potencializar a interação entre seres humanos e sistemas socioculturais, assegurada a todos, independentemente de suas necessidades sensoriais ou cognitivas. Localizada na área superior da interface, e estando sempre disponível aos usuários, a barra de acessibilidade configura-se como um dos diferenciais da Plataforma Place, agregando as seguintes funcionalidades:

(1) Recursos de interação e comunicação, que podem ser acessados por meio de atalhos via teclado. Essa estratégia de implementação permite que usuários com limitação visual, e que por isso utilizam leitores de tela, ou aqueles com problemas motores, possam deslocar-se com maior agilidade entre as três diferentes áreas do ambiente: Menu de Ferramentas (tecla F), Barra de Acessibilidade (tecla A) e Área de Conteúdo (tecla C).

(2) Link para arquivos de vídeo em Libras, que descrevem as principais informações sobre a ferramenta em que o usuário se encontra.

(3) Link para arquivos de áudio, que oferecem o mesmo conteúdo presente no vídeo em Libras, visando a facilitar o acesso aos sujeitos com limitação visual.

(4) Mapa do sistema, que possibilita ao usuário visualizar a representação hierárquica da estrutura da Plataforma Place, mostrando a distribuição das áreas e das ferramentas e apontando o caminho mais simples a ser percorrido pelo usuário para acesso às funcionalidades do sistema.

A arquitetura funcional Plataforma Place (Figura 3) foi idealizada para responder às fragilidades apontadas por professores com e sem limitações quando em interação com a plataforma anteriormente utilizada para o desenvolvimento do curso. Ao mesmo tempo em que as tradicionais ferramentas de mediação para a modalidade EsD foram trabalhadas sob os critérios de usabilidade e acessibilidade, novos recursos foram incorporados para que a cultura da participação tivesse impulso também em um contexto de formação docente. Ilustra essa preocupação a inserção da ferramenta Quadro-Branco para a produção síncrona, coletiva e colaborativa para a Web (SANTAROSA, CONFORTO e MACHADO, 2014).

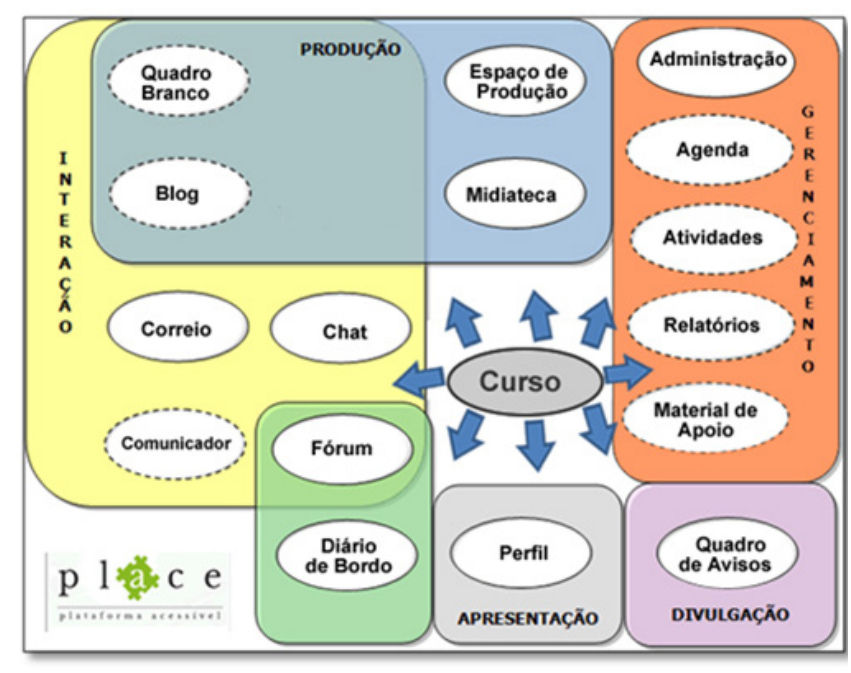

Figura 3. Arquitetura funcional da Plataforma Acessível Sistema Place (Fonte: NIEE/UFRGS)

$\mathrm{Na}$ edição de 2014, o Curso de Formação de Professores em Tecnologia da Informação e Comunicação Acessíveis cumpre uma das importantes etapas para a implementação de um sistema Web acessível: a validação com usuários reais, com a vantagem de que esse processo ocorreu em um efetivo contexto de formação docente na modalidade a distância. Para isso, 75 professores e seis integrantes da equipe de tutoria, formadores e tutores, construíram sua trajetória de conquista da fluência em tecnologias digitais acessíveis, permitindo que a equipe de desenvolvimento do NIEE obtivesse um feedback do público-alvo para o qual esse projeto de interface $\mathrm{EaD}$ se destina.

No sentido de otimizar o processo de validação da acessibilidade e usabilidade da Plataforma Place, um grupo de professores cursistas e tutores com limitação 
física, visual e auditiva passou a analisar o projeto gráfico e a funcionalidade de sua interface. A Figura 4 apresenta o perfil desse grupo de validação.

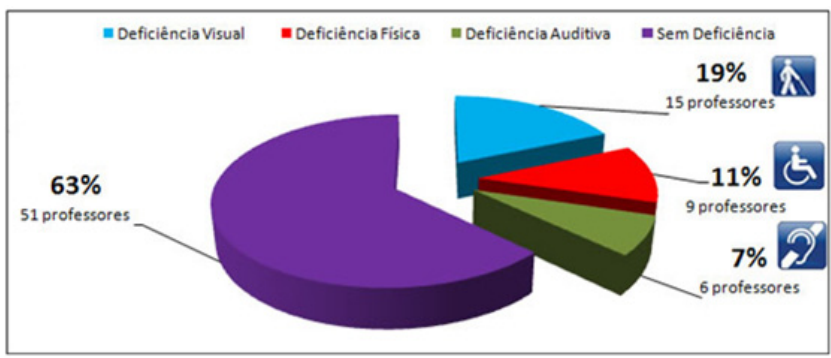

Figura 4. Perfil do grupo de validação da acessibilidade e usabilidade da Plataforma Place

Metodologicamente, a validação da acessibilidade e da usabilidade da Plataforma Place configurou-se como uma pesquisa de abordagem qualitativa, de objetivo exploratório, justificada pela valorização da relação dinâmica entre o recurso tecnológico e o pesquisado. Ratificando, assim, o vínculo indissociável entre a objetividade do recurso e as práticas de subjetivação; uma ação que não pode ser traduzida e reduzida a dados numéricos. Como instrumentos de coleta de dados, destacam-se: a utilização da observação direta, a aplicação de questionários on-line e a utilização da técnica de Grupos Focais.

A positividade dos resultados do processo de validação da Plataforma Place é evidenciada pelas palavras de um docente cego que tem uma história de proximidade com o processo de formação em tecnologias digitais acessíveis construída pela interação com interfaces digitais e perfis diferentes na modalidade EaD. Inicialmente, como um aluno explorando as funcionalidades das plataformas Moodle e TelEduc e, posteriormente, como tutor, valendo-se dos recursos da Plataforma Place para mediar o processo de aprendizagem de professores com e sem deficiência:

\footnotetext{
“[...] não percebo incompatibilidade do leitor de tela que utilizo, NVDA, com a plataforma Place. Navego com segurança, utilizando as teclas de navegação, o que me tem permitido deslocar com maior agilidade de uma área para outra, possibilitado acessar e interagir com os recursos de uma forma bastante tranquila. Como quando fui aluno do curso, utilizava as ferramentas de outras plataformas, comparativamente, percebo vantagens com a Plataforma Place." [Tutor VDM - Edição 2014]
}

Ao conceber a Plataforma Acessível Place, a equipe de desenvolvimento tecnológico do NIEE/UFRGS ratificou a observação de Castellano e Montoya (2011), pesquisadores que, ao investigar a interação de pessoas com deficiência com recursos computacionais, revelaram a importância em romper com a lógica do software/sistema exclusivo para a educação especial. Programas com a etiqueta "centrados no déficit", mesmo que apresentem vantagens, uma vez que são fáceis de usar e parecem solucionar o problema em foco, na verdade atestam sua fragilidade ao não acompanhar o desenvolvimento do usuário e ao não potencializar a interação com os demais utilizadores.

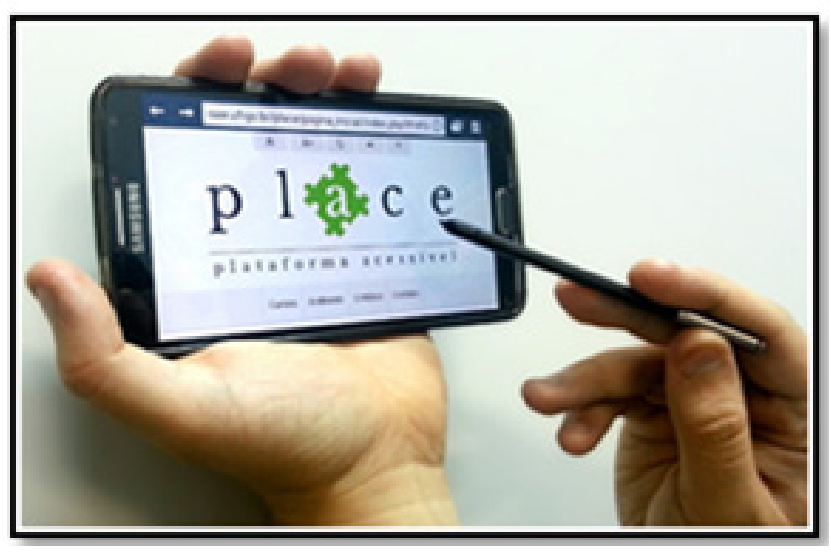

Figura 5. Compatibilidade da Plataforma Place com dispositivo móvel

No processo de implementação da Plataforma Place foi garantida sua compatibilidade com diferentes configurações tecnológicas: computadores e dispositivos móveis (Figura 5). O retorno da formadora do curso a respeito do acesso de uma professora cega em capacitação sobre tecnologias digitais acessíveis por meio de dispositivo móvel ilustra a relevância de aspectos que o sistema Place vem cumprindo: êxito do consorciamento com leitores de tela e responsividade do sistema.

"Olá, D.C., tudo bem? Gostaria de compartilhar contigo, L.S. e grupo de programadores o que a cursista L., usuária de leitores de telas, publicou ao final da sua atividade referente ao módulo 4 sobre a acessibilidade do Place: 'PS: Estou fora de casa e postando via iPad. Não possuo pacote Office e estou colando o conteúdo aqui. Tenho que informar que a plataforma é bem acessível por meio do leitor de telas VoiceOver'." [Formadora E. - Edição 2014]

Atualmente, o cenário social, econômico e cultural tem contribuído para que o discurso inclusivo seja facilmente disseminado, pois, como observa Touraine (2009), todos são instruídos a reconhecer as diferenças e a proteger as minorias. Entretanto, a equipe do NIEE/ UFRGS afastou-se dessa perspectiva naturalizada para a 
inclusão, ao modelar uma plataforma EaD que impulsiona o reconhecimento de grupos minoritários, como indivíduos portadores do direito, para que eles possam se constituir em sujeitos sociais. Se a constituição de um sujeito, como afirma Vygotsky (1998), ocorre na interação com seus pares e em diferentes espaços socioculturais, o conceito desencadeador do projeto que culminou na modelagem da Plataforma Place reside em edificar esse princípio também para contextos de formação na modalidade $\mathrm{EaD}$.

\section{CONCLUSõES}

A Plataforma Place, ao promover a interação de usuários com e sem deficiência, abandona a configuração tecnológica restritiva para o público-alvo da educação especial, que, ao centrar-se no defeito, condiciona uma interação segregadora às pessoas com deficiência. Pela efetiva busca de concretização do conceito de acessibilidade nesse sistema Web, práticas de empoderamento docente e de equidade social conquistaram uma nova interface digital.

Cada ação de acessibilidade viabilizada na estruturação do Curso de Formação de Professores em Tecnologias de Informação e de Comunicação Acessíveis e no desenvolvimento da Plataforma Place concretiza metas assumidas pelo NIEE/UFRGS na perspectiva da educação inclusiva: (1) forjar um novo modo de ser professor, isto é, desenhar um profissional que assuma e defenda os valores da diversidade em sua interface multi e intercultural; (2) projetar um educador perspicaz e problematizador de seu fazer e de sua realidade escolar e social, para a construção de uma docência coletiva e cooperativa, sintonizada com a educação na e para a diversidade humana; (3) instituir um processo de conquista da fluência digital para educadores, com e sem deficiência, em diferentes municípios brasileiros, para que eles possam configurar e operacionalizar apoios externos, não para resolver as especificidades de alunos com deficiência, mas para impulsionar movimentos de transformação do cenário escolar, no sentido de edificar a Cultura da Participação; (4) estabelecer o movimento de ruptura com a configuração de apoio terapêutico para a deficiência, centrada nos limites e não nas possibilidades humanas, para delinear uma rede de apoio colaborativa e de enfoque institucional; (5) priorizar a construção de um modelo de apoio externo processual, com a promoção de ações educativas de caráter preventivo e formativo, por meio de um direcionamento muito mais para a formação do professor do que para o aluno com deficiência.

Os resultados que começam a ser projetados com a construção e utilização da Plataforma Place revelam o potencial de um instrumento de inclusão sociodigital para as pessoas com deficiência, especialmente para a formação no âmbito cognitivo e socioafetivo. Investigações em sistema Web acessíveis são fundamentais e necessárias para orientar ações governamentais no âmbito educacional e tecnológico, contribuindo internacionalmente, em especial com os países ibero-americanos, para o intercâmbio de espaços digitais acessíveis.

\section{REFERÊNCIAS}

BRASIL. MEC/SEESP. Secretaria de Educação Especial. Política Nacional de Educação Especial na Perspectiva da Educação Inclusiva. 2007. Disponível em: <http://peei.mec. gov.br/arquivos/politica_nacional_educacao_especial.pdf>. Acesso em: 19 ago. 2014.

BOURDIEU, P. A escola conservadora: as desigualdades frente à escola e à cultura. In: NOGUEIRA, M. A.; CATANI, A. M. Escritos de educação. 2. ed. Petrópolis: Vozes, 1999. p. 39-64. CASTELLANO, R. E.; MONTOYA, R. S. Laptop, andamiaje para la Educación Especial: guía práctica, computadoras móviles en el currículo. Organización de las Naciones Unidas para la Educación la Ciencia y la Cultura (Unesco). Montevideo, Uruguay, 2011.

FREIRE, P. Pedagogia da autonomia: saberes necessários à prática educativa. Rio de Janeiro: Paz e Terra, 1996.

O'REILLY, T. What is Web 2.0 - design patterns and business models for the next generation of software. O'Reilly Publishing, 2005. Disponível em: <http://www.oreillynet.com/lpt/a/6228>. Acesso em: 15 ago. 2014.

RODRIGUES, D. Dez ideias (mal) feitas sobre a educação inclusiva. In: RODRIGUES, D. (Org.). Inclusão e educação: doze olhares sobre a educação inclusiva. São Paulo: Summus, 2009.

SANTAROSA, L. M. C.; CONFORTO, D; MACHADO, R. P. Whiteboard: synchronism, accessibility, protagonism and collective authorship for human diversity on Web 2.0. Computers in Human Behavior, v. 31, p. 591-601, 2014.

SANTAROSA, L. M. C.; CONFORTO, D. Formação de professores em tecnologias digitais acessíveis. Porto Alegre: Evangraf, 2012.

SONZA, A. P. Ambientes virtuais sob a perspectiva de usuários com limitação visual. Porto Alegre, 2008. Tese (Doutorado em Informática na Educação) - Universidade Federal do Rio Grande do Sul. Centro Interdisciplinar de Novas Tecnologias. Programa de Pós-Graduação em Informática na Educação. Porto Alegre, 2008.

TOURAINE, A. Pensar outramente: o discurso interpretativo dominante. Petrópolis, RJ: Vozes, 2009.

VALENTE, J. A.; ALMEIDA, F. J. Visão analítica da informática na educação no Brasil: a questão da formação do professor. Revista Brasileira de Informática na Educação, Sociedade Brasileira de Computação (RS), n. 1, p. 1-28, set. 1997.

VYGOTSKY, L. S. A formação social da mente: o desenvolvimento dos processos psicológicos superiores. São Paulo: Martins Fontes, 1998.

W3C. Recomendações de acessibilidade para conteúdo Web (WCAG) 2.0. 2009. Disponível em: <http://www.ilearn.com. br/TR/WCAG20/>. Acesso em: 20 ago. 2014.

Recebido em 25-01-2016

Aprovado em 09-04-2017. 